\title{
Papel de los tejidos orales durante la infección por SARS-CoV-2.
}

\section{Role of oral tissues in SARS-CoV-2 infection.}

\author{
Luis Ángel Ortiz López,* Luis Alberto Morales León,* David Fernando Palazuelos Ramírez,* \\ José Francisco Lam Rascón,* Luis Alberto Castillo Díaz*
}

\section{RESUMEN}

La actual pandemia de COVID-19 provocada por el virus SARS-CoV-2 es un problema de salud que afecta a la población globalmente. Su desarrollo puede ser asintomático o exhibir manifestaciones clínicas moderadas o severas dependiendo en gran medida de la respuesta inmune de quien la padece. Esta enfermedad afecta principalmente a los pulmones a través del desarrollo del síndrome respiratorio agudo severo (SRAS), tanto como por la «tormenta de citocinas», una respuesta inflamatoria exacerbada que podría provocar una falla multisistémica y, en casos severos, la muerte. Se conoce que la enzima convertidora de angiotensina 2 (ECA-2), presente en diversos tejidos del cuerpo, actúa como receptor funcional del virus SARS-CoV-2 facilitando la entrada de éste a las células. Se ha demostrado la presencia de dicho receptor en varios tejidos orales, por lo que se puede considerar a la cavidad bucal como una vía latente de infección por dicho coronavirus, ya que su mecanismo de transmisión es a través de la inhalación de partículas virales, ya sea por vía nasal u oral. Así mismo, la presencia de carga vírica en la saliva y algunos de los síntomas de la COVID-19, por ejemplo la ageusia, pueden indicar la presencia de contagio viral en etapas tempranas. La presente revisión muestra evidencia que sugiere que diversos tejidos en la cavidad oral podrían ser considerados sitios potenciales de contagio por el SARS-CoV-2, teniendo un papel importante en el mecanismo de transmisión y en el desarrollo de coinfecciones.

Palabras clave: COVID-19, SARS-CoV-2, enzima convertidora de angiotensina 2, infección, oral, tejidos.

\section{ABSTRACT}

The COVID-19 pandemic caused by the SARS-CoV-2 virus is currently a global healthcare problem. The onset of this disease can exhibit several clinical manifestations ranging from mild to severe symptoms, depending on the individual's immune response. COVID-19 primarily affects the lungs by developing the Severe Acute Respiratory Syndrome (SARS) and the "cytokine storm», an exacerbated inflammatory reaction that can lead to multiorgan failure and consequently death. The angiotensin-converting enzyme 2 (ACE-2), present in several tissues in the human body, is known to act as the functional receptor of the SARS-CoV-2 germ facilitating its entrance into the cells. Such receptor is also present in diverse oral cavity tissues, indicating a latent route of infection due to its influence in the transmission mechanism by inhalation, either oral or nasal, of virus particles. Also, viral load in saliva and taste disorder symptoms like ageusia could indicate a viral infection in its early stages. This article presents evidence suggesting that several tissues in the oral cavity can be considered potential sites of SARS-CoV-2 infection, thus playing an essential role in the transmission mechanism and development of co-infections.

Keywords: COVID-19, SARS-CoV-2, angiotensin-converting enzyme 2, infection, oral, tissues.

\section{INTRODUCCIÓN}

$\mathrm{L}$ os coronavirus (CoVs) pertenecen a un grupo de virus con un genoma (RNA) de cadena simple, son responsables de causar enfermedades respiratorias y tienen la capacidad de infectar a humanos y a una amplia variedad de animales. A finales del año 2019, en Wuhan, China, se reportaron varios casos de infecciones del tracto

\footnotetext{
* Departamento de Medicina y Ciencias de la Salud. División de Ciencias Biológicas y de la Salud. Universidad de Sonora.

Recibido: 14 de abril de 2021. Aceptado: 30 de abril de 2021.
}

Citar como: Ortiz LLÁ, Morales LLA, Palazuelos RDF, Lam RJF, Castillo DLA. Papel de los tejidos orales durante la infección por SARS-CoV-2. Rev ADM. 2021; 78 (3): 167-175. https://dx.doi.org/10.35366/100075 
respiratorio que fueron diagnosticados como neumonías atípicas. Sin embargo; poco tiempo después, el Centro de control de enfermedades en China identificó un nuevo tipo de coronavirus denominado 2019-nCoV, como agente causal de dichas infecciones. A principios de 2020, la Organización Mundial de la Salud (OMS) declaró a la infección por SARS-CoV-2 como una pandemia debido a su rápida propagación. ${ }^{1-3}$ Actualmente, la enfermedad denominada COVID-19 producida por el virus SARSCoV-2 ha sido un problema de salud pública y privada importante en muchos países durante el año 2020, y que aún sigue vigente. Datos epidemiológicos de la OMS, a principios de 2021, reportan un total de 103'362,039 de casos confirmados y un total de 2'244,713 de muertes. El lector es referido a la página oficial de la OMS para mayor detalle de la presente información: https://www. who.int/emergencies/diseases/novel-coronavirus-2019/ situation-reports).

El aumento de casos a nivel mundial ha llevado a esfuerzos por encontrar estrategias adecuadas para el control de la transmisión del virus, ya sea a través del confinamiento o la reducción de la movilidad en el espacio público, tiempo en el que se ha tratado de encontrar un tratamiento efectivo contra el germen. Se sabe que el mecanismo de transmisión de dicho coronavirus ocurre tras la exposición a los aerosoles generados a través de la tos y estornudos de personas portadoras del virus, los cuales podrían inhalarse por la vía nasal o introducirse por la cavidad oral, respectivamente. ${ }^{4}$ Tras el contagio, los infectados pueden desarrollar síntomas o no, en el primer caso, algunas señales clínicas incluyen fiebre, dificultad para respirar, mialgia y síntomas secundarios como la anosmia y ageusia. Sin embargo, la enfermedad es capaz de evolucionar y conducir a manifestaciones severas, entre las que destaca la falta de oxigenación por el desarrollo del síndrome respiratorio agudo severo (SRAS) debido a una reacción inmune deficiente y un estado inflamatorio severo conocido con el nombre de «tormenta de citocinas», requiriendo hospitalización y con un pronóstico de recuperación menos favorable. ${ }^{5-7}$

El estado actual de la pandemia, el aumento de los casos reportados y muertes, han puesto como prioridad el desarrollo de vacunas efectivas contra el SARS-CoV-2. La mayoría de estas vacunas son elaboradas para actuar como antagonistas de proteínas estructurales virales; el uso de virus inactivados, los ADN o ARNm virales o adenovirus no replicativos son otras estrategias ampliamente utilizadas en este contexto. Por lo general, es difícil poder desarrollar una vacuna en tan poco tiempo, ya que se deben valorar aspectos tales como la seguridad, los efectos de protección, dosis adecuada y efectividad. Normalmente estos procesos son evaluados en tres fases de ensayos clínicos, los cuales pueden tomar algunos años en desarrollarse. ${ }^{8}$ En octubre de 2020 se tenía registro de diez vacunas, las cuales ya habían sido aprobadas en las fases I y II de experimentación en humanos y se encontraban en fase III, de las cuales se pueden destacar la vacuna BNT162b1 (BioNTech/Fosun Pharma/Pfizer), Gamaleya's Sputnik V, Covaxin, ChAdox1, Ad-5, entre otras. Debido al éxito de dichas vacunas para producir inmunogenicidad con escasos efectos adversos, ${ }^{9}$ algunas de ellas ya están disponibles en el mercado para ser distribuidas y aplicadas en varios países.

Existe evidencia científica que sugiere que el SARSCoV-2 puede internalizarse en los tejidos orales, siguiendo un patrón de contagio semejante al observado durante la infección de las vías aéreas. ${ }^{10,11}$ Este hallazgo resulta relevante en el área biomédica ya que podría brindar alternativas de diagnóstico y tratamiento oportunos en el tratamiento de la COVID-19. ${ }^{12}$ Se sabe asimismo que algunos tejidos bucales, tales como la lengua, glándulas salivales, piso de la boca y el epitelio gingival actúan como reservorios del virus en la fase temprana de la contaminación por tal germen, interesantemente, antes de la aparición de síntomas de la enfermedad. ${ }^{10,13}$ Por lo que es importante conocer la interacción del virus con los sitios potenciales de contagio presentes en los tejidos de la boca, y su posible mecanismo de propagación, donde destaca el papel que tiene la saliva en el desarrollo de la transmisión viral, al igual que en las posibles secuelas o manifestaciones clínicas que se presentan en los tejidos bucales después de la infección por el coronavirus SARS-CoV-2.

\section{VIRUS SARS-CoV-2}

El SARS-CoV-2 es un virus perteneciente a la familia de $B$ Coronaviridae, el cual incluye un genoma de RNA de una cadena simple. Las partículas de este coronavirus tienen una apariencia redonda u ovalada, de un diámetro entre 60-100 nm. Los análisis filogenéticos del genoma viral demuestran que el 79.5 y $50 \%$ de las secuencias de este coronavirus coinciden con las secuencias de SARS-CoV y MERS-CoV, respectivamente, definiendo a estas tres especies de virus como B-Coronavirus. ${ }^{14}$ Se ha comprobado también que el SARS-CoV-2 comparte segmentos de RNA con coronavirus proveniente del murciélago (BatCoV RaTG13), por lo que se atribuye al contagio por SARS-CoV-2 un origen zoonótico, incluyendo al pangolín como posible animal de infección intermediario. ${ }^{15}$ 
Dicho coronavirus contiene proteínas estructurales, las cuales tienen por función el ensamblaje vírico y la liberación de partículas virales hacia las células hospederas. ${ }^{1}$ Del mismo modo, el virus posee una nucleocápside compuesta de ARN genómico y de proteína nucleocápside fosforilada $(\mathrm{N})$ que se encuentra dentro de una bicapa de fosfolípidos cubierta por dos tipos de proteínas de espícula (del inglés «S») y hemaglutinina esterasa (por sus siglas en inglés $\mathrm{HE}$ ). Las proteínas de membrana y de envoltura (E) se localizan entre las proteínas S (Figura 1). ${ }^{14}$

La proteína $S$ presente en este germen es de especial relevancia ya que cuenta con el dominio de unión a su receptor (por sus siglas en inglés RBD), el cual es la enzima convertidora de angiotensina 2 (ECA-2) presente en las células huésped. La proteína S cuenta con dos subunidades; la subunidad 1 (S1) que ayuda a la unión a la ECA-2. Después de la unión del virus a su receptor ECA-2, la subunidad S2 fusiona la partícula viral con la membrana de la célula del huésped, lo que culmina con la liberación del contenido vírico en el citoplasma celular. ${ }^{5}$ Se conoce que el mecanismo de entrada a la célula depende igualmente de proteasas como las catepsinas y la proteasa serina transmembrana 2 (por sus siglas en inglés TMPRSS2). Además, SARS-CoV-2 contiene proteínas no estructurales, ejemplo de éstas son las proteasas, ARN polimerasa, helicasa y otro tipo de proteínas involucradas en la transcripción y replicación del genoma viral, que ayudan en la maduración del virus, para posteriormente ser liberado de la célula por exocitosis. ${ }^{4}$

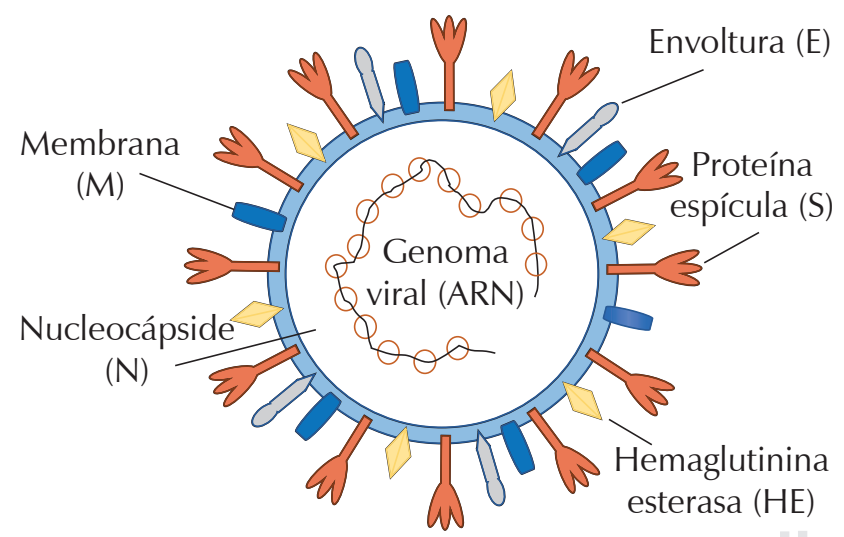

Figura 1: Representativa de la estructura de los betacoronavirus. El virión contiene proteínas estructurales, un ARN genómico de cadena simple y una proteína nucleocápside fosforilada (N) subyacente a una bicapa de fosfolípidos, lugar donde se encuentran los dos tipos de proteínas de espícula (S). Las proteínas de membrana, envoltura (E) y la hemaglutinina esterasa (HE), se localizan entre las proteínas $\mathrm{S}$, característica que brinda a este tipo de virus la apariencia de «corona».

\section{FISIOPATOLOGÍA DE LA INFECCIÓN POR SARS-COV-2}

Como se mencionó, la evolución del contagio en pacientes con COVID-19 puede ser asintomático o exhibir un espectro de manifestaciones clínicas moderadas y serias. En la evolución de las más severas, estas personas podrían requerir hospitalización por falta de una oxigenación adecuada, debida al desarrollo del síndrome respiratorio agudo severo (SARS) y daño pulmonar asociado a un proceso inflamatorio sistémico agravado. La infección por el SARS-CoV-2 se presenta en las vías respiratorias, principalmente en el epitelio bronquial (neumocitos tipo II ECA-2) y del epitelio endotelial. Inicialmente, la contaminación vírica induce una respuesta inmune innata, en la que las células infectadas reconocen al RNA viral como un patrón molecular asociado a daño. ${ }^{16}$ Esto favorece la liberación de interferones antivirales como el interferón gama (IFN $\gamma$ ) y diferentes quimiocinas que favorecen el reclutamiento de leucocitos polimorfonucleares, monocitos, macrófagos, células dendríticas, asesinas naturales, linfocitos cooperadores y citotóxicos, los cuales contribuyen para erradicar la infección. ${ }^{6,17}$

Ya que la entrada del virus a la célula huésped se realiza por medio del receptor la ECA-2, la activación del sistema renina-angiotensina (SRA) induce un aumento en la inflamación y la permeabilidad vascular. La expresión del receptor ECA-2 se puede identificar en distintas células y tejidos del organismo, entre los que se incluyen las alveolares tipo II del pulmón, las del epitelio estratificado del esófago, enterocitos del íleon y colon, colangiocitos, células del miocardio, las del túbulo proximal del riñón y del urotelio de la vejiga. ${ }^{18}$ Los cambios patológicos ocurridos durante la infección por SARS-CoV-2 en los diferentes órganos están fuertemente relacionados con los efectos sistémicos derivados de una reacción inmune exacerbada contra el virus. ${ }^{19}$ Se ha demostrado también que después de la inoculación por este coronavirus, la expresión de ECA-2 disminuye; sin embargo, la expresión de ECA no disminuye, lo que favorece la conversión de angiotensina I (Ang I) a angiotensina II (Ang II), y en consecuencia se produce un aumento en la permeabilidad vascular, lo cual está asociado con daño pulmonar agudo. ${ }^{14,19}$ El contagio viral es capaz de inducir piroptosis, con la consecuente liberación de citocinas inflamatorias, por ejemplo la interleucina 1 beta (IL-1 $\beta){ }^{16}$

La activación de la respuesta inmune adaptativa se acompaña de una sobreproducción de citocinas inflamatorias, lo que clínicamente se conoce como síndrome respiratorio agudo severo (SRAS). ${ }^{6}$ Esta llamada «tormenta 
de citocinas» se caracteriza por la producción exacerbada de varias citocinas y quimiocinas, entre las que se incluyen a las interleucinas 2, 7, 10 (IL-2, IL-7, IL-10), el factor estimulante de colonia de granulocitos, la proteína inducida por interferón gama 10, la proteína quimiotáctica de monocitos 1, la proteína inflamatoria de macrófagos alfa y el factor de necrosis tumoral alfa plasmático. Dichas citocinas producen inflamación en las vías respiratorias y otros órganos, lo que finalmente puede desencadenar un choque séptico y falla multisistémica acompañada de una reacción inmune adaptativa deficiente. ${ }^{16}$ Dicha respuesta adaptativa es orquestada por los linfocitos $T$ y B. Las células $\mathrm{T}$ citotóxicas $\left(\mathrm{CD}^{+}\right)$son responsables de atacar directamente a las células infectadas por el virus, mientras que los linfocitos T cooperadores $\left(\mathrm{CD} 4^{+}\right)$ producen citocinas que favorecen el reclutamiento de linfocitos adicionales, así como de células del sistema inmune innato. Así, una vez activados los linfocitos B por las células dendríticas, y aquellas presentadoras de antígeno, éstos maduran en forma de células plasmáticas capaces de producir inmunoglobulinas neutralizantes del isotipo M (IgM) como primera línea de defensa durante los primeros seis días de infección. Después, en un promedio de cuatro a ocho días, dichas células generan anticuerpos IgG anti-nucleocápside y antiproteína S viral de alta afinidad y memoria. No obstante, se ha reportado también la producción de anticuerpos neutralizantes dos semanas después del inicio de los síntomas clínicos. ${ }^{16}$

Un contagio provocado por una nueva cepa del virus podría retar significativamente a la inmunidad humoral. Se ha sugerido que esto podría ocurrir durante varias infecciones víricas como SARS-CoV, MERS-CoV y DENV, ${ }^{20}$ y a este fenómeno se le conoce con el nombre de potenciación dependiente de anticuerpos. Esta evolución consiste de un aumento en la transmisión y replicación viral derivado de una actividad de anticuerpos no neutralizantes subóptima o de una cantidad insuficiente de ellos. Esto puede desarrollarse durante la captación de complejos antígeno-anticuerpo a través de los receptores Fc expresados en las membranas de ciertas células inmunitarias como los macrófagos. ${ }^{21}$ Las mutaciones en sitios críticos del dominio de unión al receptor podrían explicar dicho incremento en la afinidad de unión del complejo formado por el coronavirus y los anticuerpos no neutralizantes a los receptores Fc gama (Fcylla) y no necesariamente al receptor ECA-2. Así, varios factores, los cuales incluyen afinidad, concentración, y especificidad de los anticuerpos producidos después del contagio, podrían favorecer el desarrollo de este proceso. ${ }^{22}$ Actualmente, se desconoce el mecanismo preciso por el cual podría presentarse dicho fenómeno con relación a la infección por SARS-CoV-2, y se requieren estudios suplementarios que permitan el desarrollo de terapias basadas en anticuerpos monoclonales, plasma convaleciente y vacunas. ${ }^{23}$

Se sabe que los virus tienen la capacidad de migrar a través de las vías neuronales afectando los nervios motores y sensoriales. Ejemplo de esto es la conexión entre la cavidad nasal y el sistema nervioso central. ${ }^{24} \mathrm{En}$ dicha cavidad, las células no neuronales del epitelio nasal están íntimamente relacionadas con el bulbo olfatorio, el cual está involucrado en las funciones olfatorias del sistema nervioso central, sugiriendo que la entrada del germen por la vía nasal puede llegar a afectar esta zona por la propagación de la infección al cerebro anterior y por lo tanto a la función olfatoria. No obstante que la expresión de la ECA-2 en los nervios olfatorios y el bulbo olfatorio es escasa, ${ }^{12}$ se cree que la afectación de las células no neuronales del epitelio nasal pudiera influir en el proceso de señalización de las neuronas sensitivas olfatorias, o bien eso podría derivarse de una afectación en los capilares (por la expresión de la ECA-2 en el endotelio capilar) adyacentes al epitelio nasal produciendo la anosmia característica de la COVID-19.12 Actualmente, existe evidencia de que la cavidad oral tiene un papel relevante en el progreso del contagio por SARS-CoV-2, en este supuesto, la evidencia sugiere que algunos tejidos bucales pueden ser un sitio de acceso para el virus, y algunas manifestaciones clínicas orales podrían brindar luz con relación a la fisiopatología de dicho germen y el subsecuente desarrollo de ese trastorno. ${ }^{11,13,18,19,25}$

\section{ESTRUCTURAS ORALES COMO POTENCIAL ENTRADA DE INFECCIÓN VIRAL}

El SARS-CoV-2 se aloja predominantemente en la mucosa nasal, bucal y faríngea durante los primeros 10 días de infección, después, el virus se aloja progresivamente en los pulmones. ${ }^{10}$ Debido a que la cavidad de la boca es un reservorio de bacterias patógenas, se cree que éstas podrían inducir coinfecciones en pacientes que padecen la COVID-19. Ambas microbiotas, la oral y la orofaríngea son similares a las presentes en las vías respiratorias, por lo que se sugiere que las bacterias orales podrían alterar la homeostasis de la microbiota del sistema respiratorio y, por consiguiente, la expresión de citocinas inflamatorias en la mucosa respiratoria. ${ }^{26}$ Se ha revelado la expresión del receptor la ECA-2 en la cavidad bucal, en particular en la mucosa, las glándulas salivales, la lengua y el piso de la boca. ${ }^{18}$ Como se mencionó, dicho receptor es crucial para la infectividad del SARS-CoV-2, la interacción de 


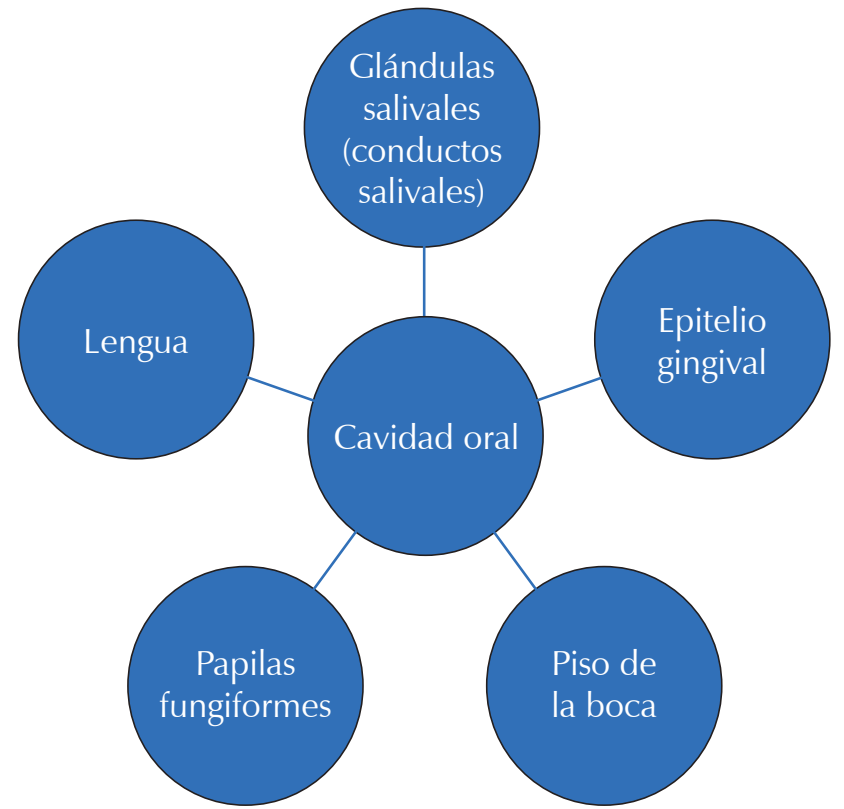

Figura 2: Representativa de los sitios potenciales de infección por SARS-CoV-2 en la cavidad oral.

ECA-2 con la proteína de espícula $\mathrm{S}$ es favorecida por la proteasa furina que está presente en diversos tejidos orales. Sakaguchi y colaboradores, en un estudio donde examinaron muestras del dorso de la lengua, epitelio gingival, glándulas submandibulares y saliva, reportaron que la furina se localizó principalmente en muestras de esa secreción y en la lengua. Se observó igualmente expresión de ECA-2, TMPRSS2 y furina en células cultivadas derivadas de papilas gustativas tanto como en el epitelio gingival, ${ }^{11}$ por lo que se sugiere que la cavidad de la boca es un sitio latente para la transmisión e infección de SARS-CoV-2 (Figura 2).

En ese mismo estudio se observó la expresión difusa de la ECA-2 en la membrana de las células de la capa superficial de la lengua, mientras que en la capa espinobasal fue en el núcleo y citoplasma en las células del epitelio escamoso de la lengua fue donde mayormente se observó su expresión. A excepción las células basales, todas ellas fueron positivas para la proteasa sérica transmembrana 2 (TMPRSS2). En el caso de la furina, ésta se encontró en el citoplasma de las células de la capa espinobasal de la lengua y no en las superficiales, infiriendo por esta misma razón que la TMPRSS2 podría tener un papel más significativo en la evolución de la infección, el cual puede estar limitado a las células en su superficie. ${ }^{11} \mathrm{La}$ lengua es un órgano que abarca gran parte de la cavidad bucal, una zona que es susceptible a la transmisión del virus. Un dato interesante es que el dorso de la lengua es un nicho para los microorganismos orales, donde la microflora predominante incluye la presencia de bacterias como Prevotella y Veillonella y se sabe también que el ambiente bacteriano es capaz de influir en el desarrollo de coinfecciones del tracto respiratorio por el contagio de SARS-CoV-2. ${ }^{26}$ Además, el estado de inflamación sistémica crónica asociada con la enfermedad periodontal puede presuponer un riesgo de mayor gravedad en pacientes que padecen la COVID-19, por la posibilidad de agravamiento de la respuesta inflamatoria que provoca la contaminación por dicho coronavirus. ${ }^{10}$ La placa dentobacteriana contiene patógenos, por ejemplo $P$. gingivalis, que podrían agravar el estado de una neumonía, ya que las gingipaínas, producidas por ese cocobacilo gramnegativo, inducen un proceso inflamatorio crónico. Así, los hábitos de higiene oral deficientes podrían contribuir a la acumulación de diversos microorganismos periodontales que serían capaces de acelerar un declive de la función pulmonar en enfermos con COVID-19. ${ }^{26}$

Así mismo, la interacción del virus en las papilas gustativas fungiformes pudiera representar también un mecanismo de infección viral y podría explicar la disfunción de las respuestas sensitivas del gusto en pacientes que padecen COVID-19. Notablemente, la ageusia no se había reportado en personas infectadas por otros tipos de coronavirus, por ejemplo, SARS-CoV o MERS-CoV. Por lo que este tipo de desorden quimiosensitivo podría representar un síntoma característico del contagio por SARS-CoV-2 en una etapa temprana. ${ }^{25}$ Con relación a la contaminación de las glándulas salivales por este coronavirus, un estudio realizado en macacos demostró que las células ECA-2 y citoqueratina que recubren los conductos de las glándulas salivales son células diana y un reservorio de dicho tipo de germen en etapas tempranas del contagio. ${ }^{13}$ Se ha verificado igualmente que el número de receptores ECA-2 en dichas glándulas puede ser mayor que en los pulmones, así, los hallazgos descritos sugieren fuertemente que tales glándulas podrían ser también un reservorio importante de SARS-CoV-2 en pacientes asintomáticos. ${ }^{10}$

Por otro lado, una alta carga viral en la saliva y las secreciones nasales podrían ser factores adicionales involucrados en el desarrollo de alteraciones bucales asociadas con la infección por SARS-CoV-2. ${ }^{27}$ Esta secreción humana es un fluido corporal producido por las glándulas salivales formada principalmente de agua (9499\%), moléculas orgánicas (0.5\%) e inorgánicas (0.2\%). Entre las principales funciones de la saliva se incluyen la 
digestión de los alimentos, la lubricación de la mucosa bucal y el mantenimiento de la homeostasis de la cavidad de la boca. ${ }^{11}$ Además, dicho fluido facilita la agregación de la microbiota oral para favorecer la eliminación de microorganismos. ${ }^{28,29}$ Sin embargo, ese líquido incluso actúa como un nicho ecológico para la colonización y la proliferación de microorganismos. Las mucinas salivales, y las proteínas glicosiladas presentes en la saliva, proporcionan fuentes de carbono y nitrógeno para el crecimiento y metabolismo de la microbiota oral. ${ }^{29}$ Hasta el momento, se han identificado más de 700 especies microbianas en la saliva, muchas de las cuales son planctónicas y una vez que forman biopelículas pueden generar enfermedades bucales. La biopelícula adquirida en tal fluido consta de varias proteínas, como la proteína ácida rica en prolina, estaterina e histatinas, las cuales actúan como nutrientes para los microorganismos, favoreciendo su reproducción, metabolismo y adherencia a la superficie de los dientes. ${ }^{28}$

Estudios recientes han confirmado la presencia de SARS-CoV-2 en la saliva, particularmente, la presencia del virus se ha identificado en los conductos de las glándulas que la producen, en el líquido crevicular gingival (de la encía) y en las secreciones del tracto respiratorio superior e inferior que se combinan con la saliva. ${ }^{30}$ Además, se ha encontrado la presencia de ARN de ese coronavirus en la saliva de pacientes con COVID-19 sin lesiones pulmonares, lo que potencialmente podría explicar la identificación de personas asintomáticas con la enfermedad. ${ }^{29,30}$ La evidencia reciente sugiere fuertemente que dicho líquido bucal tiene un papel determinante en la transmisión de SARS-CoV-2 por gotículas salivales, ${ }^{28}$ y que el tamaño de dichas gotículas es determinante en la transferencia viral. Gotas grandes con un diámetro mayor a $60 \mu \mathrm{m}$, transferidas a distancias cortas o que tocan superficies infectadas, propagan la mayoría de las infecciones respiratorias transmisibles. Este tipo de gotas parecen depositarse rápidamente en el aire. Las gotas pequeñas, con un diámetro menor o igual a $60 \mu \mathrm{m}$, pueden causar una transmisión viral de corto alcance con una distancia menor a un metro. Por otro lado, cada expectoración podría producir alrededor de 3,000 núcleos de gotículas salivales, que es el equivalente a la cantidad generada durante una charla de cinco minutos. Así mismo, cada estornudo es capaz de producir aproximadamente 40,000 gotas de este fluido, cubriendo varios metros en el aire. Importantemente, una exhalación regular podría crear gotas del líquido que superan una distancia de un metro en el aire. Así, las gotículas salivales pueden entrar en la boca, los ojos o inhalarse directamente en los pulmones. ${ }^{29}$
Ensayos moleculares a partir de muestras de lavado de garganta y saliva, revelaron que el contenido de ARN del SARS-CoV-2 en este fluido es más alto que en muestras de lavado de garganta, lo que puede tener un impacto significativo en la posibilidad de transmisión del virus. ${ }^{28}$ También se ha determinado la presencia de ARN de este germen en muestras de aire, confirmando la transmisión del coronavirus por el viento. ${ }^{28}$ Por lo tanto, todo indica que el SARS-CoV-2 podría transmitirse por aerosoles a corta o larga distancia. ${ }^{28,31}$ Finalmente, se ha reportado que la hiposalivación juega un papel importante en la susceptibilidad a infecciones virales, entre las que se incluyen a las infecciones respiratorias. Baghizadeh Fini sugiere que la secreción reducida de esa saliva puede alterar las superficies de la mucosa oral, lo cual pudiera promover la colonización vírica. Dicha hiposalivación además podría dificultar la secreción de péptidos y proteínas antimicrobianas, lo que podría conducir a infecciones oportunistas, incluyendo la del SARS-CoV- $2 .{ }^{29}$

\section{DIAGNÓSTICO DE COVID-19 A PARTIR DE LA SALIVA}

Estudios recientes han reportado que la COVID-19 puede detectarse a partir de muestras salivales, hasta el momento se conocen tres métodos de captura de saliva: hisopos de saliva, toser y directamente desde el conducto de la glándula de origen. El fluido obtenido desde los conductos de las glándulas productoras es compatible con el diagnóstico de COVID-19 agudo y con una confiabilidad aceptable. En las aplicaciones clínicas que requieren de una fuerte tasa positiva de identificación viral, la saliva aislada desde la garganta profunda proporciona una tasa positiva de infección significativa, lo que podría facilitar el diagnóstico temprano de ese contagio. ${ }^{29}$ Así mismo, el análisis del fluido crevicular gingival también proporciona un método de diagnóstico no invasivo. El líquido crevicular gingival puede recolectarse mediante varias técnicas, una de las más comunes es la de absorción empleando tiras o puntos de papel. ${ }^{30}$ Un ejemplo del uso de este fluido como herramienta de diagnóstico de SARS-CoV-2 es un estudio reciente, que reportó la presencia de SARS-CoV-2 en la saliva de pacientes confirmados con COVID-19 hasta 11 días después de su hospitalización. ${ }^{30}$

Dichas estrategias de detección viral ofrecen ventajas significativas para la medicina, ya que no son invasivas y las muestras salivales puede ser fácilmente obtenidas, incluso por las propias personas afectadas. ${ }^{29}$ En un estudio en Japón, donde evaluaron la duración de la carga vírica en pacientes hospitalizados que padecieron de la 
enfermedad, se demostró por pruebas moleculares que dos de ellos continuaron presentando carga de virus aun cuando ya no presentaban síntomas. Se identificó que dichos pacientes no tenían una salud oral regular por lo que, al reforzar sus técnicas de higiene bucal, las pruebas de PCR resultaron negativas a los pocos días. No obstante, dicha relación entre la higiene oral y la disminución de la carga viral aún no está del todo establecida debidamente, por lo que se requieren estudios posteriores, con un número mayor de casos, a fin de confirmar que dicha correlación es contundente. ${ }^{32}$

\section{REPORTES RECIENTES DE CASOS CLÍNICOS Y MANIFESTACIONES ORALES EN PACIENTES INFECTADOS CON SARS-COV-2}

En una revisión sistemática, ${ }^{25}$ se estableció que los signos y síntomas asociados a trastornos orales en pacientes con COVID-19 incluyen desórdenes del gusto, como ageusia, ulceraciones bucales inespecíficas, gingivitis descamativa, petequias y el desarrollo de coinfecciones. Sin embargo, aún no es claro si algunas de las manifestaciones clínicas orales en pacientes con la enfermedad son consecuencia de una infección por SARS-CoV-2 o son derivadas de las comorbilidades sistémicas que dichos enfermos padecían previamente. ${ }^{33}$ En el contagio por SARS-CoV-2, el proceso inflamatorio se ha asociado con la hiperpigmentación de la mucosa bucal. ${ }^{34}$ Se ha reportado que la expresión de diferentes mediadores de la inflamación, tales como TNF- $\alpha$, interleucina 1 alfa (IL- $1 \alpha$ ), prostaglandinas, leucotrienos, entre otras citocinas, puede verse aumentada durante la melanogénesis de la mucosa oral en pacientes diagnosticados con COVID-19 que son sintomáticos. ${ }^{35}$ Galván-Casas y equipo ${ }^{36}$ identificaron lesiones cutáneas (vesículas hemorrágicas, máculas purpúricas, pústulas, pápulas infiltrantes, urticarias y necrosis), así como enantemas virales en la mucosa oral. Así mismo, Chaux-Bodard y colegas $^{37}$ reportaron lesiones ulcerativas y vesiculobullosas en la cavidad bucal en sujetos confirmados y sospechosos de infección por SARS-CoV-2. ${ }^{34,38}$

En el caso de los adultos mayores, se sabe que estos pueden presentar candidiasis, la cual podría deberse a una disminución inherente en la efectividad de su sistema inmunitario. ${ }^{34,38}$ Debido a la presencia y distribución de células receptoras del virus en la cavidad bucal, esto puede tener un papel significativo en el desarrollo de la infección, iniciando con la respuesta inmune, también reacciones inflamatorias en órganos y tejidos relacionados, dígase la mucosa de la lengua y las glándulas salivales. ${ }^{33}$ Esto pudiese contribuir potencialmente a resultados adversos relacionados con la salud bucal, que probablemente conduzcan a diversas infecciones micóticas oportunistas, infecciones recurrentes por el virus del herpes simple oral (VHS-1), ulceraciones orales inespecíficas, erupciones, disgeusia, xerostomía, ulceraciones y gingivitis como resultado del sistema inmunológico deteriorado $y / 0$ mucosa bucal susceptible. ${ }^{39}$

Recientemente, se reportó un caso clínico de una paciente de 43 años, positiva para SARS-CoV-2, quien presentó fiebre, malestar general, disgeusia, anosmia, diarrea y neumonía. Los estudios de gabinete reportaron riesgo de trombosis y la paciente permaneció en cuarentena. Entre las manifestaciones clínicas orales observadas en dicha persona también se incluyen lesiones aftosas, sensación de ardor y depilación de la lengua. Derivado de esto, se le medicó con colutorios con acetónido de triamcinolona al $0.05 \%$, tres veces al día por 10 días. Se reportó que después de dicho tratamiento la depapilación lingual persistió, pero las úlceras aftosas y la sensación de ardor cedieron. ${ }^{40}$ En otro ejemplo, un paciente de 53 años, positivo para SARS-CoV-2, refirió sensación de ardor bucal y fisuras comisurales unilaterales. Se registraron anosmia y disgeusia en buena concordancia con el caso clínico previo. En este caso, las lesiones orales diagnosticadas incluyeron queilitis comisural y se prescribió un ungüento con neomicina, nistatina y acetónido de triamcinolona. Igualmente se indicó al paciente el uso de clorhexidina entre cada aplicación de ungüento. Las lesiones comisurales desaparecieron después del tratamiento pero, interesantemente, tanto la anosmia como la disgeusia persistieron. ${ }^{40}$

Así mismo, una paciente de 78 años, positiva para SARS-CoV-2, reportó xerostomía intensa, lesiones en lengua, paladar y comisuras, las cuales son manifestaciones clínicas características de candidiasis pseudomembranosa y queilitis angular. En este caso, se indicaron soluciones y geles que comúnmente contienen carboximetilcelulosa, goma xantana, mucinas, hidroxietilcelulosa, óxido de polietileno o aceite de linaza para mejorar la sequedad salival. ${ }^{41}$ La queilitis angular se trató con un ungüento que contenía neomicina, nistatina y acetónido de triamcinolona. De la misma manera se prescribieron enjuagues con solución de nistatina por 15 días a fin de tratar las lesiones intraorales. Después del tratamiento, las lesiones pseudomembranosas y las fisuras comisurales desaparecieron, con la consiguiente reversión de la xerostomía..$^{40}$ Una mujer de 78 años resultó positiva para el SARS-CoV-2, con ingreso hospitalario en los primeros días de abril del 2020. Desde la hospitalización refirió una sensación muy intensa de boca seca que no tenía previamente. Duran- 
te la consulta odontológica se observaron lesiones en lengua, paladar y comisura, compatibles con candidiasis pseudomembranosa y queilitis angular. En este caso, se prescribieron soluciones y geles para mejorar la sequedad salival, y también enjuagues con solución de nistatina cuatro veces al día para las lesiones intraorales durante 15 días. La queilitis angular se trató con un ungüento que contenía neomicina, nistatina y acetónido de triamcinolona. Tras el tratamiento desaparecieron las lesiones pseudomembranosas y las fisuras comisurales. Además, mejoraron el flujo salival y la sensación de boca seca.

Finalmente, en un estudio reciente realizado por Giacomelli y su equipo, se evaluó la prevalencia de alteraciones gustativas y olfativas en 59 personas con COVID-19 (tanto hospitalizados como no hospitalizados). En contraste con los estudios previos aquí discutidos, en este caso, ninguno de los pacientes refirió padecer de úlceras bucales o lesiones vesiculobullosas (a los pacientes se les hizo una historia clínica oral y ninguno mencionó esas complicaciones). Esto puede sugerir que dichas manifestaciones orales no están relacionadas directamente por la infección con SARS-CoV-2. Así, descartar una relación entre los signos clínicos orales con la contaminación por este coronavirus es importante para prevenir diagnósticos y tratamientos terapéuticos erróneos por los odontólogos tratantes. ${ }^{42}$ Con base a lo discutido aquí, más estudios adicionales son necesarios para determinar la posible relación directa entre las manifestaciones bucales con el desarrollo de la enfermedad, ya que de acuerdo a la literatura discutida, dichos signos orales podrían ser consecuencia de una inmunosupresión causada por el SARS-CoV-2 y no directamente por la infección del virus. Como lo explica Aceli al-Katib, es poco probable que los institutos de salud pública puedan identificar todos los casos de manifestaciones orales que potencialmente puedan presentarse en pacientes que sufren de COVID-19 globalmente (Schemel-Suárez M. López-López J. y Chimenos-Küstner E. 2015).

\section{CONCLUSIONES}

El epitelio de la boca expresa el receptor ECA2, particularmente en la mucosa, la lengua, y las glándulas salivales, por lo que la cavidad bucal parece ser una vía de entrada directa para el SARS-CoV-2. Esto también es respaldado por la evidencia que demuestra que la interacción de la proteína $S$ de dicho coronavirus con su receptor es facilitada por la enzima furina, la cual está presente en los tejidos de la boca. Comprender el mecanismo de infección de SARS-CoV-2, y otros de la familia de los coronavirus, resulta relevante para poder encontrar alternativas de diagnóstico y tratamiento a fin de hacer frente a este tipo de infecciones. La microbiota bucal parece tener un papel determinante en el desarrollo de coinfecciones tras el contagio por ese germen, así como en la respuesta inmunológica que se dispara después de la contaminación viral. Los signos clínicos orales en pacientes con COVID-19, discutidos aquí, brindan un panorama significativo de la consecuencia o impacto que puede tener el SARS-CoV-2 en la salud bucal y sistémica de pacientes que padecen de este trastorno. Así, entre los síntomas orales relevantes relacionados con la COVID-19, la ageusia parece ser un síntoma inequívoco resultante de dicha patología, no obstante, la evidencia discutida sugiere que otros síntomas clínicos bucales podrían estar directa o indirectamente relacionados con la enfermedad. Estudios suplementarios, sumados a la colaboración multidisciplinaria entre la industria farmacéutica y los centros de investigación, son necesarios para confirmar dicha relación entre la infección por SARS-CoV-2 y varias manifestaciones orales reportadas.

\section{REFERENCIAS}

1. Rehman MFU, Fariha C, Anwar A, Shahzad N, Ahmad M, Mukhtar $S$ et al. Novel coronavirus disease (COVID-19) pandemic: a recent mini review. Comput Struct Biotechnol J. 2021; 19: 612-623.

2. Dong E, Du H, Gardner L. An interactive web-based dashboard to track COVID-19 in real time. Lancet Infect Dis. 2020; 20 (5): 533-534.

3. A Chen Y, A Liu Q, A Guo D. Emerging coronaviruses: genome structure, replication, and pathogenesis. J Med Virol. 2020; 92 (4): 418-423.

4. Shereen MA, Khan S, Kazmi A, Bashir N, Siddique R. COVID-19 infection: Origin, transmission, and characteristics of human coronaviruses. J Adv Res. 2020; 24: 91-98.

5. García LF. Immune response, inflammation, and the clinical spectrum of COVID-19. Front Immunol. 2020; 11: 1441.

6. Huang C, Wang Y, Li X, Ren L, Zhao J, Hu Y et al. Clinical features of patients infected with 2019 novel coronavirus in Wuhan, China. Lancet. 2020; 395 (10223): 497-506.

7. Pascarella G, Strumia A, Piliego C, Bruno F, Del Buono R, Costa F et al. COVID-19 diagnosis and management: a comprehensive review. J Intern Med. 2020; 288: 192-206.

8. Awadasseid A, Wu Y, Tanaka Y, Zhang W. Current advances in the development of SARS-CoV-2 vaccines. Int J Biol Sci. 2021; 17 (1): 8-19.

9. Rawat K, Kumari P, Saha L. COVID-19 vaccine: a recent update in pipeline vaccines, their design and development strategies. Eur J Pharmacol. 2021; 892: 173751.

10. Herrera D, Serrano J, Roldán S, Sanz M. Is the oral cavity relevant in SARS-CoV-2 pandemic? Clin Oral Investig. 2020; 24 (8): 29252930.

11. Sakaguchi W, Kubota N, Shimizu T, Saruta J, Fuchida S, Kawata A et al. Existence of SARS-CoV-2 entry molecules in the oral cavity. Int J Mol Sci. 2020; 21 (17): 6000.

12. Kanjanaumporn J, Aeumjaturapat S, Snidvongs K, Seresirikachorn K, Chusakul S. Smell and taste dysfunction in patients with 
SARS-CoV-2 infection: a review of epidemiology, pathogenesis, prognosis, and treatment options. Asian Pac J Allergy Immunol. 2020; 38 (2): 69-77.

13. Li Liu QW, Xavier Alvarez, Haibo Wang, Yanhua Du, Hua Zhu, Hong Jiang et al. Epithelial cells lining salivary gland ducts are early target cells of severe acute respiratory syndrome coronavirus infection in the upper respiratory tracts of rhesus macaques. J Virol. 2011; 85 (8): 4025-4030.

14. Jin Y, Yang H, Ji W, Wu W, Chen S, Zhang W et al. Virology, epidemiology, pathogenesis, and control of COVID-19. Viruses. 2020; 12 (4): 372.

15. Zhou P, Yang X-L, Wang X-G, Hu B, Zhang L, Zhang W et al. A pneumonia outbreak associated with a new coronavirus of probable bat origin. Nature. 2020; 579 (7798): 270-273.

16. Tay MZ, Poh CM, Rénia L, MacAry PA, Ng LFP. The trinity of COVID-19: immunity, inflammation and intervention. Nat Rev Immunol. 2020; 20 (6): 363-374.

17. Asselah T, Durantel D, Pasmant E, Lau G, Schinazi RF. COVID-19: Discovery, diagnostics and drug development. J Hepatol. 2021; 74 (1): 168-184.

18. Xu H, Zhong L, Deng J, Peng J, Dan H, Zeng X et al. High expression of ACE2 receptor of 2019-nCoV on the epithelial cells of oral mucosa. Int J Oral Sci. 2020; 12 (1): 8.

19. Hamming I, Timens W, Bulthuis ML, Lely AT, Navis G, van Goor $\mathrm{H}$. Tissue distribution of ACE2 protein, the functional receptor for SARS coronavirus. A first step in understanding SARS pathogenesis. J Pathol. 2004; 203 (2): 631-637.

20. Ulrich H, Pillat MM, Tárnok A. Dengue Fever, COVID-19 (SARS-CoV-2), and antibody-dependent enhancement (ADE): a perspective. Cytometry A. 2020; 97 (7): 662-667.

21. Fu Y, Cheng Y, Wu Y. Understanding SARS-CoV-2-mediated inflammatory responses: from mechanisms to potential therapeutic tools. Virol Sin. 2020; 35 (3): 266-171.

22. Karthik K, Senthilkumar TMA, Udhayavel S, Raj GD. Role of antibody-dependent enhancement (ADE) in the virulence of SARS-CoV-2 and its mitigation strategies for the development of vaccines and immunotherapies to counter COVID-19. Hum Vaccin Immunother. 2020; 16 (12): 3055-3060.

23. Lee WS, Wheatley AK, Kent SJ, DeKosky BJ. Antibody-dependent enhancement and SARS-CoV-2 vaccines and therapies. Nat Microbiol. 2020; 5 (10): 1185-1191.

24. Wu Y, Xu X, Chen Z, Duan J, Hashimoto K, Yang L et al. Nervous system involvement after infection with COVID-19 and other coronaviruses. Brain Behav Immun. 2020; 87: 18-22.

25. Amorim Dos Santos J, Normando AGC, Carvalho da Silva RL, Acevedo AC, De Luca Canto G, Sugaya N et al. Oral manifestations in patients with COVID-19: a living systematic review. J Dent Res. 2020: 100 (2): 141-154.

26. Bao L, Zhang C, Dong J, Zhao L, Li Y, Sun J. Oral microbiome and SARS-CoV-2: beware of lung co-infection. Front Microbiol. 2020; 11: 1840.

27. Cruz Tapia RO, Peraza Labrador AJ, Guimaraes DM, Matos Valdez LH. Oral mucosal lesions in patients with SARS-CoV-2 infection. Report of four cases. Are they a true sign of COVID-19 disease? Spec Care Dentist. 2020; 40 (6): 555-560.
28. Li YQ, Ren B, Peng X, Hu T, Li JY, Gong T et al. Saliva is a nonnegligible factor in the spread of COVID-19. Mol Oral Microbiol. 2020; 35 (4): 141-145.

29. Baghizadeh Fini M. Oral saliva and COVID-19. Oral Oncol. 2020; 108:104821.

30. Vinayachandran D, Balasubramanian S. Salivary diagnostics in COVID-19: Future research implications. J Dent Sci. 2020; 15 (3): 364-366.

31. Tuan P, Horby $P$, Dinh P, Mai L, Zambon M, Shah J et al. SARS transmission in Vietnam outside of the healthcare setting. Epidemiol Infect. 2007; 135 (3): 392-401.

32. Warabi Y, Tobisawa S, Kawazoe T, Murayama A, Norioka R, Morishima R et al. Effects of oral care on prolonged viral shedding in coronavirus disease 2019 (COVID-19). Spec Care Dentist. 2020; 40 (5): 470-474.

33. Dos Santos JA, Normando AGC, da Silva RLC, De Paula RM, Cembranel AC, Santos-Silva AR et al. Oral mucosal lesions in a COVID-19 patient: New signs or secondary manifestations? Int J Infect Dis. 2020; 97: 326-328.

34. Chandran R, Feller L, Lemmer J, Khammissa RAG. HIV-associated oral mucosal melanin hyperpigmentation: a clinical study in a South African population sample. AIDS Res Treat. 2016; 2016: 8389214.

35. Corchuelo J, Ulloa FC. Oral manifestations in a patient with a history of asymptomatic COVID-19: case report. Int J Infect Dis. 2020; 100: 154-157.

36. Galván CCC, Carretero HA, Rodríguez-Jiménez G, FernándezNieto P, Rodríguez-Villa LD, Navarro FA et al. Classification of the cutaneous manifestations of COVID-19: a rapid prospective nationwide consensus study in Spain with 375 cases. Br J Dermatol. 2020; 183 (1): 71-77.

37. Anne-Gaelle Chaux-Bodard SD, Aline Desoutter. Oral manifestation of COVID-19 as an inaugural symptom? J Oral Med Oral Surg. 2020; 26 (2): 18

38. Martín Carreras-Presas C, Amaro Sánchez J, López-Sánchez AF, Jané-Salas E, Somacarrera Pérez ML. Oral vesiculobullous lesions associated with SARS-CoV-2 infection. Oral Dis. 2021; 27 (Suppl. 3): 710-712.

39. Dziedzic A, Wojtyczka R. The impact of coronavirus infectious disease 19 (COVID-19) on oral health. Oral Dis. 2021; 27 (Suppl 3): 703-706.

40. Diaz RM, Jimenez RA, Villarroel M. Oral manifestations associated with COVID-19. Oral Dis. 2021. Available in: https://doi. org/10.1111/odi.13555.

41. Millsop JW, Wang EA, Fazel N. Etiology, evaluation, and management of xerostomia. Clin Dermatol. 2017; 35 (5): 468-476.

42. Al-Khatib A. Oral manifestations in COVID-19 patients. Oral Dis. 2021; 27: 779-780.

Conflicto de intereses: Los autores no tienen conflicto de intereses por declarar.

Correspondencia:

José Francisco Lam Rascón

E-mail: luis.castillo@unison.mx joselam742@gmail.com 